\title{
3D printed PLA Army-Navy retractors when used as linear retractors yield clinically acceptable tolerances
}

\author{
Joshua V. Chen ${ }^{1 *}$ D, Alexis B. C. Dang ${ }^{1,2}$, Carlin S. Lee ${ }^{1}$ and Alan B. C. Dang ${ }^{1,2}$
}

\begin{abstract}
Background: Modern low-cost 3D printing technologies offer the promise of access to surgical tools in resource scarce areas, however optimal designs for manufacturing have not yet been established. We explore how the optimization of 3D printing parameters when manufacturing polylactic acid filament based Army-Navy retractors vastly increases the strength of retractors, and investigate sources of variability in retractor strength, material cost, printing time, and parameter limitations.

Methods: Standard retractors were printed from various polylactic acid filament spools intra-manufacturer and inter-manufacturer to measure variability in retractor strength. Printing parameters were systematically varied to determine optimum printing parameters. These parameters include retractor width, thickness, infill percentage, infill geometry, perimeter number, and a reinforced joint design. Estimated retractor mass from computer models allows us to estimate material cost.

Results: We found statistically significant differences in retractor strength between spools of the same manufacturer and between manufacturers. We determined the true strength optimized retractor to have $30 \%$ infill, 3 perimeters, $0.25 \mathrm{in}$. thickness, $0.75 \mathrm{in}$. width, and has "Triangle" infill geometry and reinforced joints, failing at more than 15X the threshold for clinically excessive retraction and costs \$1.25 USD.

Conclusions: The optimization of 3D printed Army-Navy retractors greatly improve the efficacy of this instrument and expedite the adoption of 3D printing technology in many diverse fields in medicine not necessarily limited to resource poor settings.
\end{abstract}

Keywords: 3D printing, Additive manufacturing, Medical devices, Surgical instruments, Optimization, Polylactic acid

\section{Background}

Current literature explores the role of 3D printing in changing the surgical landscape through the new ability to create more resource efficient in-house surgical instruments, along with anatomical models of patients that assist in training and preoperative planning, prosthetics, personalized surgical equipment better suited for patient morphologies, and 3D printed implants [1-14]. Notably, these vast strides in $3 \mathrm{D}$ printing technologies are also allowing healthcare providers to create robust, low-cost medical and surgical equipment in resource scarce areas,

\footnotetext{
* Correspondence: Joshuavchen@berkeley.edu

'Department of Orthopaedic Surgery, University of California, San Francisco, CA, USA

Full list of author information is available at the end of the article
}

such as in developing nations and in aerospace medicine where weight and space limitations exist [15-17]. 3D printing allows for rapid prototyping and manufacturing that expedites the improvement of medical equipment, examples of which are the development of better splints, syringes, and surgical suction tips [18-20]. Furthermore, it is shown that the high heat used during the 3D printing process sterilizes the final print [21]. Specifically, 3D printed polylactic acid (PLA) Army-Navy retractors offer a cheaper, lighter-weight, and more space-efficient alternative to traditional stainless steel Army-Navy retractors without compromising surgical retraction capabilities [22]. Army-Navy retractors are commonly used in a myriad of procedures involving retraction of shallow incisions and are listed at an online retail price of 
approximately \$24 USD per retractor. Though literature exists in quantifying the mechanical strength of 3D printed Army-Navy retractors, none have sought to optimize printing settings and retractor designs, which could lead to additional discussion about improving the efficacy of 3D printed surgical instruments and allow healthcare providers in resource scarce areas to adopt this technology.

\section{Methods}

\section{Software and design}

Army-Navy retractor models were designed in Autodesk $^{\ominus}$ Fusion $360^{\text {mi }}$ (Autodesk ${ }^{\ominus}$, Inc.). Standard Tessellation Language (STL) files of these models were exported from Autodesk Fusion 360 and imported into Slic3r Prusa Edition - 1.38.7-prusa3d (Prusa Research), a software that processes STL files into thin slices that can then be converted into g-codes, a numerical control programming language that provides spatial instructions to the $3 \mathrm{D}$ printer to guide the printing process, ultimately building the print one layer at a time. All prints in this study have layer heights of $0.15 \mathrm{~mm}$. Print settings were systematically varied in Slic3r Prusa Edition to produce unique g-codes and ultimately determine the most strength optimal print settings for our designed PLA Army-Navy retractors.

Control retractors are set to have $20 \%$ infill, 2 perimeters, a "Grid" infill geometry, "Rectilinear" top/bottom fill pattern, default Slic3r Prusa Edition print settings, and are oriented horizontally so that no support material is needed (Fig. 1a, c). Infill geometry, infill percent, and perimeter number were changed, respectively, with all other parameters held constant in Slic3r Prusa Edition. For retractors with reinforced joints (Fig. 1b), differing retractor widths, and differing retractor thicknesses, separate retractor models were designed in Autodesk Fusion 360 and the corresponding STLs were imported separately into Slic3r.

\section{D printer model and hardware}

G-codes are loaded into an SD card and inserted into the Original Prusa i3 MK3 3D printer (Prusa Research) where the print can be selected and started. An Original Prusa i3 MK3 kit is priced at \$750 USD and a fully assembled Original Prusa i3 MK3 3D printer is priced at $\$ 1000$ USD. A $0.4 \mathrm{~mm}$ nozzle was used with the extruder temperature set to $235^{\circ} \mathrm{C}$ for all layers and bed temperature was set to $60^{\circ} \mathrm{C}$ for all layers. Essentium engineering grade $1.75 \mathrm{~mm}$ PLA was used, priced at $\$ 50 / \mathrm{kg}$.

\section{Mechanical testing}

Mechanical testing was performed using a NidecShimpo FGS-1000H hand wheel test stand and FG-3009 force gauge, where retractors were pulled until failure and the maximum force withstood was measured (Fig. 2). In this test stand, retractors were orientated so that the short arm of the retractor was placed on the force gauge hook and the long arm of the retractor was placed on the strap, such that the strap was as far away from the body of the retractor as possible to subject the retractors to similar torque.

Using the Nidec-Shimpo force gauge and test stand, a stainless steel Army-Navy retractor was used to determine appropriate retractor strength, with $35 \mathrm{~N}+/-5 \mathrm{~N}$ indicated by expert surgeons as strong or clinically excessive retraction causing tissue tearing and damage, based upon feel of the retractor on the surgeons' hands.

\section{Retractor sets}

Four sets of control retractors were printed to test interspool and inter-manufacturer variability; three of these sets were printed using three separate Essentium PLA filament spools, and the remaining set was printed using MakerBot PLA filament (Table 1). The estimated mass of this retractor is $10.20 \mathrm{~g}$, resulting in a material cost of $\$ 0.51$ USD without machine expenses. The time to print these retractors is approximately $1 \mathrm{~h} 20 \mathrm{~min}$. Two-tailed T-tests will be used to determine whether there exist statistically significant differences in retractor strength.

To test whether infill geometry affects retractor strength, a single $20 \%$ infill, non-reinforced, $0.25 \mathrm{in}$. thickness, $0.5 \mathrm{in}$. width, and 2 perimeter Essentium

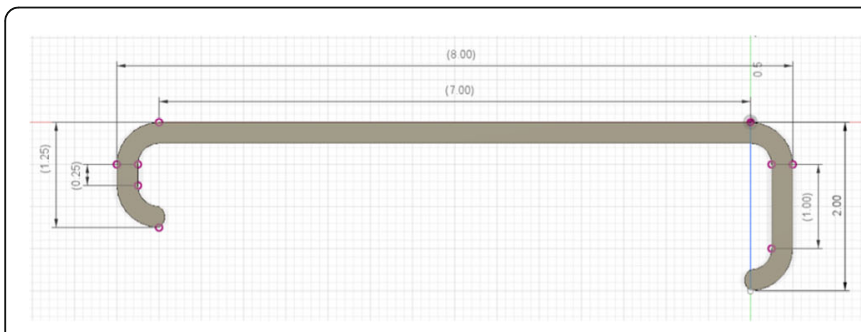

(A)

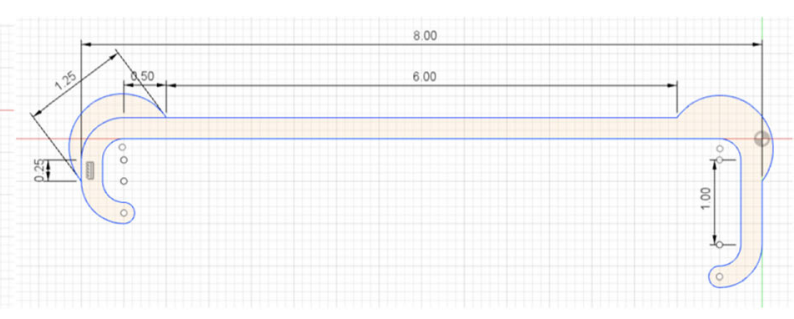

(B)

Fig. 1 a Standard retractor design and $\mathbf{b}$ reinforced retractor design in inches. c The Army-Navy retractor is oriented on the print bed horizontally such that no support material is needed 


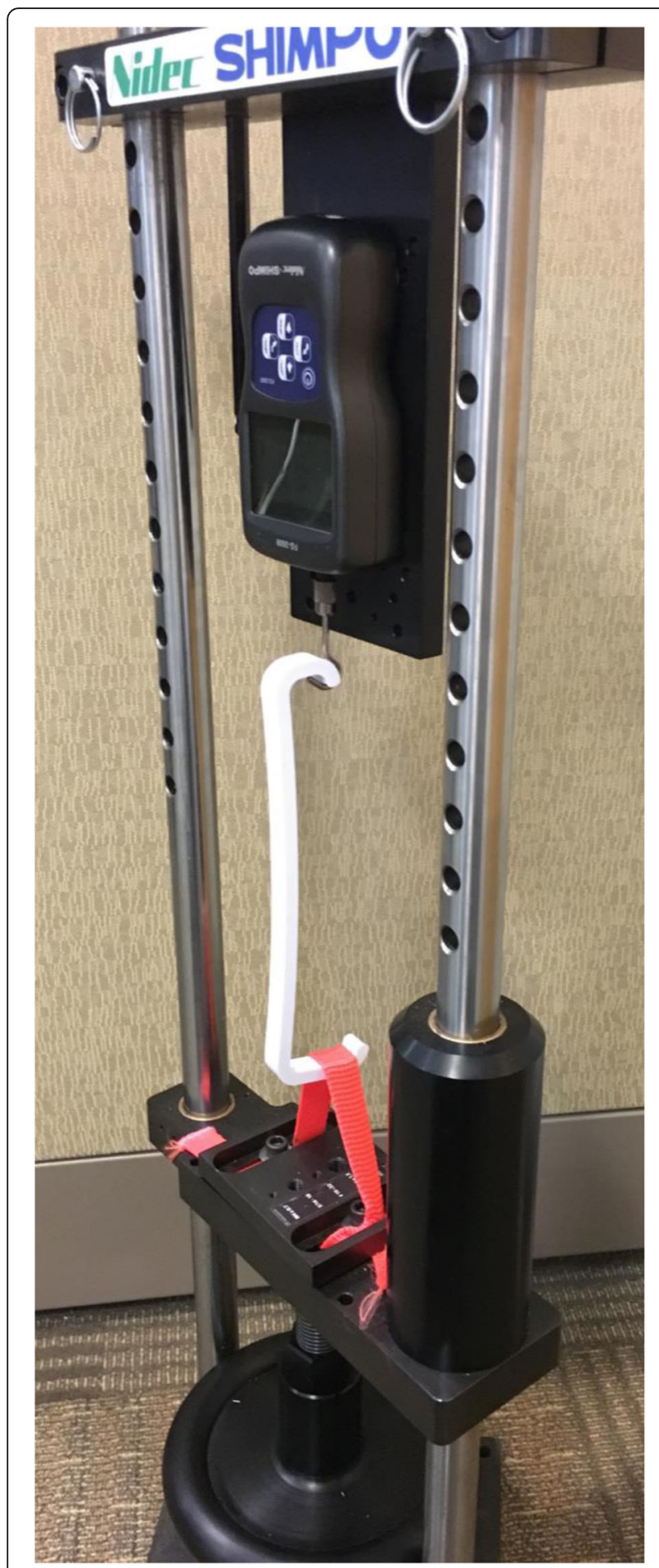

Fig. 2 Nidec-Shimpo FGS-1000H hand wheel test stand and FG3009 force gauge with oriented retractor

filament retractor was printed for eleven different geometries: Rectilinear, Grid (default), Triangles, Stars, Cubic, Line, Honeycomb, 3D Honeycomb, Hilbert Curve, Archimedean Chords, and Octagram Spiral (Fig. 3). The "Concentric" geometry was found to be unprintable due to the narrowness of the retractor. The time to print these retractors ranged from $42 \mathrm{~min}$ (Rectilinear) to $1 \mathrm{~h}$ 20 min (Grid) depending on the complexity of the infill. The following infill geometries had a print time of less than 50 min: Rectilinear, Triangle, Stars, Cubic, and Line. The following infill geometries had a print time of more than $1 \mathrm{~h}$ : Honeycomb, 3D Honeycomb, Hilbert Curve, Archimedian Chords, Octagram Spiral, and Grid.

These retractors were broken using a Nidec-Shimpo FGS-1000H hand wheel test stand and FG-3009 force gauge. From this data, the two strongest retractor geometries, "Cubic" and "Triangle", and two weakest retractor geometries, "3D Honeycomb" and "Grid", were studied further. For each of the geometries "Cubic", "Triangle", and "3D Honeycomb", twelve retractors were printed. For the "Grid" geometry, retractor data from sets number 1,2 , and 4 were combined to create an aggregate Essentium filament control set and used as comparison.

To test how infill percent affects retractor strength, sets of non-reinforced, $0.25 \mathrm{in}$. thickness, $0.5 \mathrm{in}$. width, 2 perimeter Essentium filament retractors were printed at various infill percentages (Table 2). For $20 \%$ infill, retractors from the aggregate Essentium filament control set were used. The estimated mass of the retractors varied from $8.05 \mathrm{~g}$ to $27.39 \mathrm{~g}$, resulting in a material cost of $\$ 0.40$ to $\$ 1.37$ USD without machine expenses. The time to print these retractors ranged from $40 \mathrm{~min}$ to $1 \mathrm{~h} 40$ min, increasing as infill percentage increased.

To test how perimeter number affects retractor strength, sets of $20 \%$ infill, non-reinforced, 0.25 in. thickness, and $0.5 \mathrm{in}$. width Essentium filament retractors were printed at various perimeter numbers (Table 3). Each perimeter is $0.15 \mathrm{~mm}$. For 2 perimeter retractors, retractors from the aggregate Essentium filament control set were used. The estimated mass of the retractors varied from $10.20 \mathrm{~g}$ to $17.27 \mathrm{~g}$, resulting in a material cost of $\$ 0.51$ to $\$ 0.86$ USD without machine expenses. The time to print these retractors ranged from $47 \mathrm{~min}$ to $54 \mathrm{~min}$, increasing as perimeter number increased.

To test how width affects retractor strength, sets of $20 \%$ infill, non-reinforced, 0.25 in. thickness, and 2 perimeter Essentium filament retractors were printed at various widths (Table 4). For $0.5 \mathrm{in}$. width retractors, retractors from the aggregate Essentium filament control set were used. The estimated mass of the retractors varied from $10.20 \mathrm{~g}$ to $20.39 \mathrm{~g}$, resulting in a material cost of $\$ 0.51$ to $\$ 1.02$ USD without machine expenses. The time to print these retractors ranged from $1 \mathrm{~h} 28$ min to $2 \mathrm{~h} 35 \mathrm{~min}$, increasing as width increased.

To test how thickness affects retractor strength at non-100\% infill percentages, sets of $20 \%$ infill, nonreinforced, $0.5 \mathrm{in}$. width and 2 perimeter Essentium filament retractors were printed at various thicknesses (Table 5). For 0.25 in. thickness retractors, retractors 
Table 1 Control retractor sets varied by spool and filament type

\begin{tabular}{lll}
\hline Set Number & Number of Retractors & Filament Type \\
\hline No. 1 & 7 & Essentium (Spool 1) \\
No. 2 & 5 & Essentium (Spool 2) \\
No. 3 & 10 & MakerBot PLA \\
No. 4 & 10 & Essentium (Spool 3) \\
\hline
\end{tabular}

from the aggregate Essentium filament control set were used. The estimated mass of the retractors varied from $8.08 \mathrm{~g}$ to $10.20 \mathrm{~g}$, resulting in a material cost of $\$ 0.40$ to $\$ 0.51$ USD without machine expenses. The time to print these retractors ranged from $56 \mathrm{~min}$ to $1 \mathrm{~h} 20 \mathrm{~min}$, increasing as thickness increased.

To further test how thickness affects retractor strength at $100 \%$ infill, sets of $100 \%$ infill, non-reinforced, $0.5 \mathrm{in}$. width and 2 perimeter Essentium filament retractors were printed at various thicknesses (Table 6). The estimated mass of the retractors varied from $16.80 \mathrm{~g}$ to $27.39 \mathrm{~g}$, resulting in a material cost of $\$ 0.84$ to $\$ 1.37$ USD without machine expenses. The time to print these retractors ranged from $1 \mathrm{~h} 50 \mathrm{~min}$ to $2 \mathrm{~h} 4 \mathrm{~min}$, increasing as thickness increased.
To test how reinforced joints affects retractor strength, sets of $40 \%$ infill, $0.25 \mathrm{in}$. thickness, $1 \mathrm{in}$. width, and 2 perimeter Essentium filament retractors were printed either reinforced or non-reinforced. 3 retractors were printed non-reinforced and 4 retractors were printed reinforced. The estimated mass of a non-reinforced and reinforced retractor, respectively, is $28.99 \mathrm{~g}$ and $32.78 \mathrm{~g}$, resulting in a material cost of $\$ 1.45$ and $\$ 1.64$ USD without machine expenses. The time to print these retractors ranged from $2 \mathrm{~h}$ 31 min (non-reinforced) to $2 \mathrm{~h} 43 \mathrm{~min}$ (reinforced).

\section{Results}

Inter-spool and inter-manufacturer variability

Essentium filament control retractors failed at a load of $90.7 \mathrm{~N}+/-3.3 \mathrm{~N}$. MakerBot filament control retractors

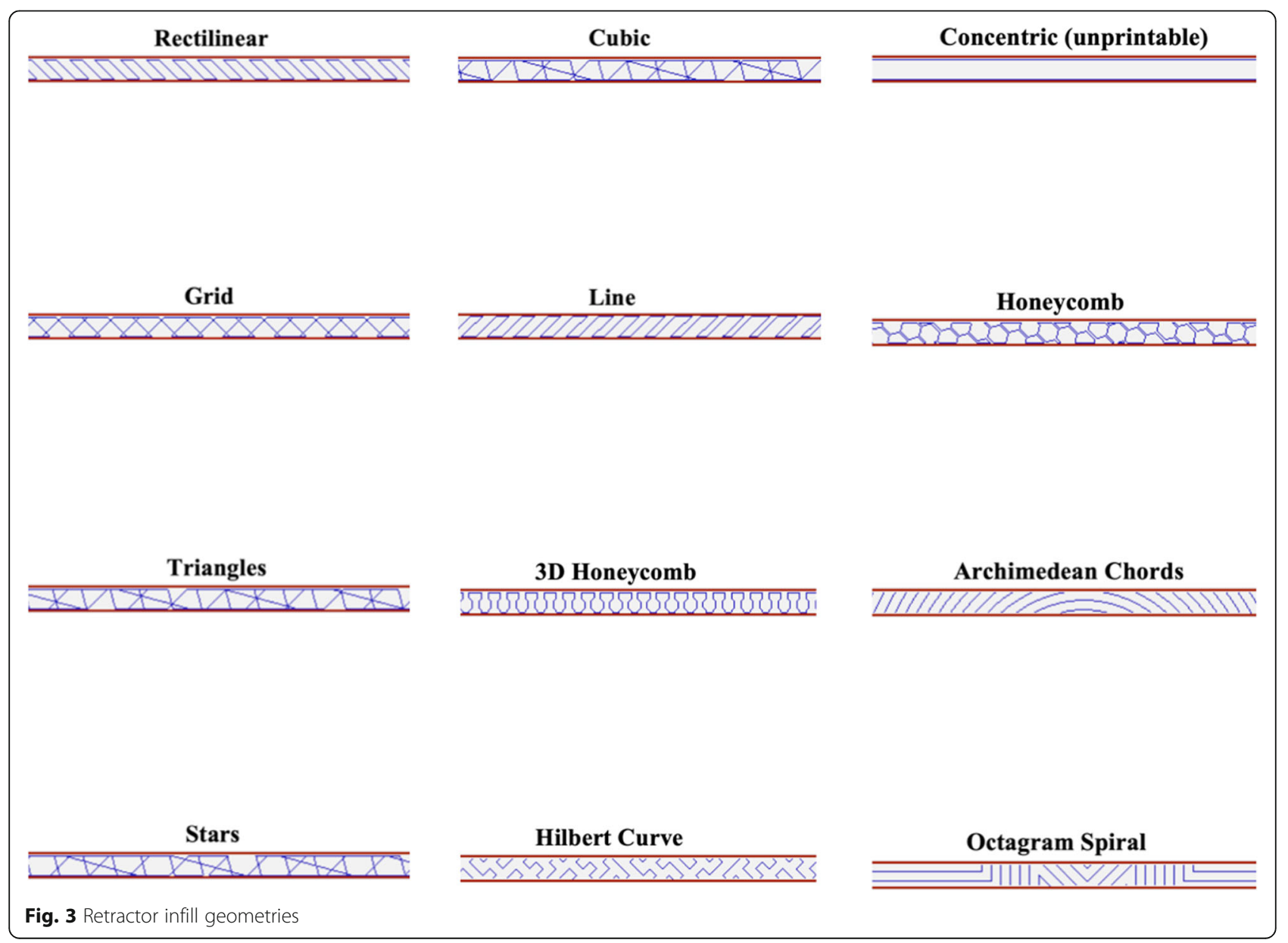


Table 2 Retractors varied by infill percentage

\begin{tabular}{llll}
\hline Number of Retractors & Infill Percentage & Estimated Mass (g) & Estimated Cost (USD) \\
\hline 4 & $10 \%$ & 8.05 & $\$ 0.40$ \\
22 & $20 \%$ & 10.20 & $\$ 0.51$ \\
4 & $60 \%$ & 18.79 & $\$ 0.94$ \\
4 & $80 \%$ & 23.09 & $\$ 1.15$ \\
4 & $100 \%$ & 27.39 & $\$ 1.37$ \\
\hline
\end{tabular}

failed at a load of $108.6 \mathrm{~N}+/-9.5 \mathrm{~N}$. All retractors in this study failed at the joint connecting the body of the retractor to the long arm (Fig. 4).

Using a two-tailed T-test, the strength of retractors in Set 1 (Essentium PLA spool 1) was found to be statistically different than Sets 2 (Essentium PLA spool 2, $p$-value $=0.0012$ ) and 4 (Essentium PLA spool 3, $p$ value $=0.0001)$; Sets 2 and 4 were not statistically different $(p$-value $=0.3783)$ (Fig. 5$)$. The Essentium filament set, an aggregation of Sets 1, 2, and 4, was statistically different than the MakerBot PLA set, set 3 (MakerBot PLA, $p$-value $=0.0002$ ) (Fig. 5). The data demonstrates statistically significant differences in retractor strength between spools of the same manufacturer and between manufacturers.

\section{Optimizing retractor parameters}

As infill percent increased, retractor strength generally increased at 2 perimeters, with a spike at $40 \%$ infill. As predicted, $10 \%$ infill resulted in the weakest retractor, and $100 \%$ infill resulted in the strongest retractor. $40 \%$ and $80 \%$ infill resulted in retractors with comparable strengths (Fig. 6a). As perimeter number increased, retractor strength increased at $20 \%$ infill (Fig. 6b). As retractor width increased, retractor strength increased up to 0.75 in. then plateaued up to 1 in. (Fig. 6c). At $20 \%$ infill, retractor thickness was most optimal at 0.2 in. (Fig. $6 \mathrm{~d})$. At $100 \%$ infill, retractor strength increased as retractor thickness increased (Fig. 6e).

A 1 in. width retractor at $40 \%$ infill failed at $330.3 \mathrm{~N}$ $+/-2.1$ N. A 1 in. width retractor at $40 \%$ infill with reinforced joints failed at $351.8 \mathrm{~N}+/-6.1 \mathrm{~N}$. At $20 \%$ infill, the two strongest geometries were "Cubic" and "Triangles", which failed at $170.0 \mathrm{~N}+/-4.8 \mathrm{~N}$ and $178.2 \mathrm{~N}+/-$ $4.2 \mathrm{~N}$ respectively; the two weakest geometries were the "3D Honeycomb" $(99.0 \mathrm{~N}+/-8.9 \mathrm{~N})$ and "Grid" (97.0 N $+/-5.7 \mathrm{~N})$.

\section{Discussion}

\section{Retractor efficacy}

All printed retractors in this optimization study have exceeded the threshold for clinically excessive retraction of $35 \mathrm{~N}$ by a large margin, at minimum by $2 \mathrm{X}$ and at maximum by $15 \mathrm{X}$ after determining optimal infill geometry, infill percentage, perimeter number, width, thickness, and design at the joints. Above $35 \mathrm{~N}$, tissue injury becomes a clinical concern. Our control retractors, printed with default settings on average failed at almost $3 \mathrm{X}$ the load and the strongest retractors required almost $15 \mathrm{X}$ the load.

Generally, higher infill percentages, increased thickness, increased width, increased perimeter number and reinforced joints each lead to increased strength, print times, and material use. Depending on the availability of resources and time, print settings can be adjusted to create a sufficiently strong retractor while reducing cost, material use, and print time. The adaptability of 3D printing to various situations in medicine is a major strength and reason to adopt this technology. This is further accompanied by the fact that 3D prints are sterilized upon heating and extruding, allowing them to be used in sterile fields, and that they are substantially lower cost than traditional stainless steel retractors $[21,22]$.

Because retractor strength was greatest at 0.2 in. thickness for $20 \%$ infill retractors and retractor strength increased as retractor thickness increased for 100\% infill retractors, we are led to conclude that the flexibility of retractors delay mechanical failure by reducing strain on the joints, the reliable point of failure. We hypothesize that the spike in retractor strength at $40 \%$ infill is also because of the bend and flex of the retractor reducing strain on the joints.

Regarding printing time, increasing perimeter number, increasing thickness, and adding reinforced joints did

Table 3 Retractors varied by perimeter number

\begin{tabular}{llll}
\hline Number of Retractors & Perimeter Number & Estimated Mass (g) & Estimated Cost (USD) \\
\hline 22 & 2 & 10.20 & $\$ 0.51$ \\
4 & 3 & 12.55 & $\$ 0.63$ \\
4 & 4 & 14.91 & $\$ 0.75$ \\
4 & 5 & 17.27 & $\$ 0.86$ \\
\hline
\end{tabular}


Table 4 Retractors varied by width (inch)

\begin{tabular}{llll}
\hline Number of Retractors & Width (in.) & Estimated Mass (g) & Estimated Cost (USD) \\
\hline 22 & 0.5 & 10.20 & $\$ 0.51$ \\
4 & 0.75 & 15.29 & $\$ 0.76$ \\
4 & 1.0 & 20.39 & $\$ 1.02$ \\
\hline
\end{tabular}

not substantially increase printing time. However, increasing width and infill percentage resulted in a marked increase in printing time, the former due to the addition of more layers and the latter increasing the time to build each layer.

\section{True optimization and limitations}

A retractor that is optimized to the greatest theoretical possible strength given the parameters in this study has $100 \%$ infill, 5 perimeters, 0.25 in. thickness, 1 in. width, and has reinforced joints. However, upon printing, it was discovered that this retractor was unprintable. This study revealed that $3 \mathrm{D}$ prints have a higher rate of failure as infill percentage increases. We believe that this may be due to the printer slicer software miscalculating the volume of plastic extruded, thereby attempting to fit greater amount of plastic in a layer than can actually fit. This then causes the plastic to overflow into upper layers, causing rough and uneven prints that may be pushed off the build plate by the extruder. Therefore, incrementally reducing infill percentage, perimeter number, and maintaining a $0.25 \mathrm{in}$. thickness in order to accommodate more plastic, we determined the true strength optimized retractor to have $30 \%$ infill, 3 perimeters, $0.25 \mathrm{in}$. thickness, $0.75 \mathrm{in}$. width, and has "Triangle" infill geometry and reinforced joints. This retractor fails at $534 \mathrm{~N}+/-28.5 \mathrm{~N}$, more than $15 \mathrm{X}$ the threshold for clinically excessive retraction, $35 \mathrm{~N}$. The estimated mass of this retractor is $24.94 \mathrm{~g}$, resulting in a material cost of $\$ 1.25$ USD without machine expenses, only $5.2 \%$ the online retail price of a stainless steel Army-Navy retractor at \$24. per unit. The time to print these retractors is approximately $2 \mathrm{~h} 14 \mathrm{~min}$.

We acknowledge that even though interspool variability exists, our retractor sets were printed randomly using different spools. Even with this variability, we were still able to derive statistically significant differences in retractor strength as parameters were varied systematically.

\section{Conclusion and future steps}

This study demonstrates how even pre-optimized 3D printed PLA Army-Navy retractors have comparable surgical retraction capabilities to stainless steel retractors, but can be created in-house at a fraction of the cost and adopted in resource poor settings. These retractors fail at a force that greatly exceeds what is required for clinically excessive retraction, $35 \mathrm{~N}$. The optimization of 3D printed Army-Navy retractors greatly improve the efficacy of this instrument and expedite the adoption of 3D technology in many diverse fields in medicine not necessarily limited to resource-poor settings. With the optimization of the 3D printed PLA Army-Navy retractor, a staple surgical instrument, researchers can pave the way towards and gain trust for an array of 3D printed medical supplies, allowing populations around the globe to receive higher quality health care and treatment.

A quantitative optimization of 3D printed Army-Navy retractors reveal their surgical capabilities to be comparable to commercial stainless steel retractors, but can be created in-house at a fraction of the cost and can be rapidly prototyped. This allows resource scarce areas to expand their access to high-quality medical equipment and direct their funds towards additional medical and social needs, improving healthcare around the world. Research on 3D printed surgical instruments opens additional discussion about the efficacy of 3D printed surgical tools and sparks a new field of research in 3D print optimization and dissemination.

Surgical use of these instruments, which are FDA class I devices, will require additional biocompatibility and sterilization validation. For medical use, this validation is done on the device level and not on the materials level. We know that PLA as a source material is biocompatible, but additives that are added to the PLA for coloring or for printability, may not be biocompatible [23]. There is data that supports that the fused deposition modeling printing process, where the thermoplastics are heated to above $200{ }^{\circ} \mathrm{C}$, in our case $235^{\circ} \mathrm{C}$ then extruded at high

Table 5 Retractors varied by thickness (inch) at 20\% infill

\begin{tabular}{llll}
\hline Number of Retractors & Thickness (in.) at 20\% In-fill & Estimated Mass (g) & Estimated Cost (USD) \\
\hline 4 & 0.15 & 8.08 & $\$ 0.40$ \\
4 & 0.2 & 9.13 & $\$ 0.46$ \\
22 & 0.25 & 10.29 & $\$ 0.51$ \\
\hline
\end{tabular}


Table 6 Retractors varied by thickness (inch) at 100\% infill

\begin{tabular}{llll}
\hline Number of Retractors & Thickness (in.) at 100\% In-fill & Estimated Mass (g) & Estimated Cost (USD) \\
\hline 4 & 0.15 & 16.80 & $\$ 0.84$ \\
4 & 0.2 & 22.07 & $\$ 1.10$ \\
4 & 0.25 & 27.39 & $\$ 1.37$ \\
\hline
\end{tabular}

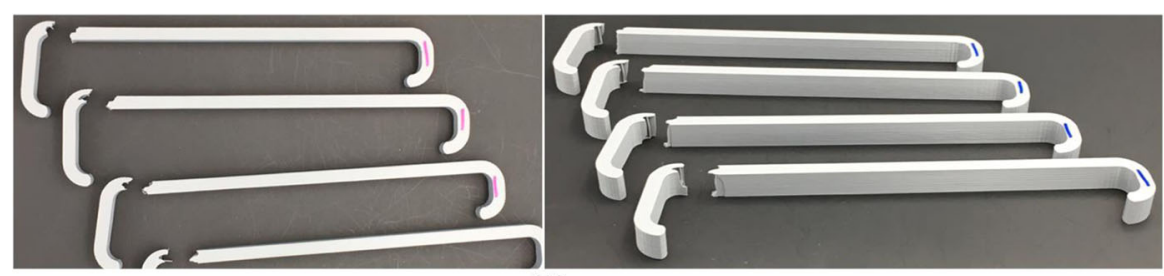

(A)
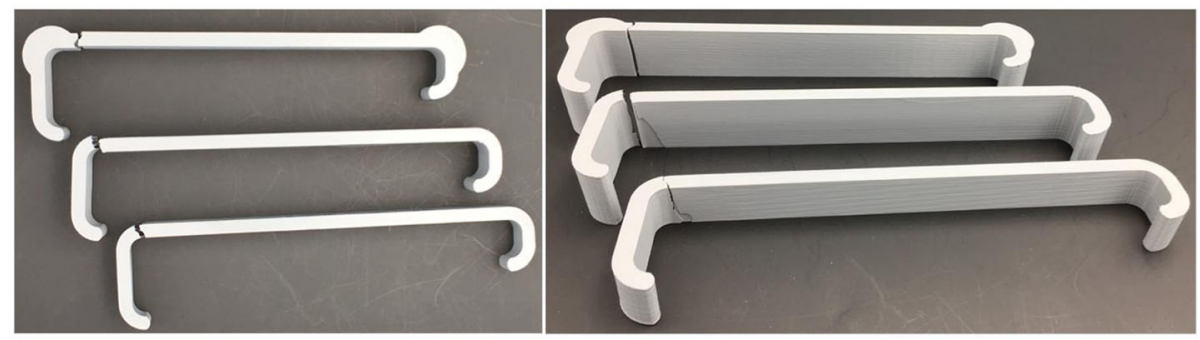

(B)

Fig. 4 a Broken standard retractors and $\mathbf{b}$ broken retractors with (top to bottom): 1 in. width with reinforced joints, 1 in. width, and 0.75 in. width

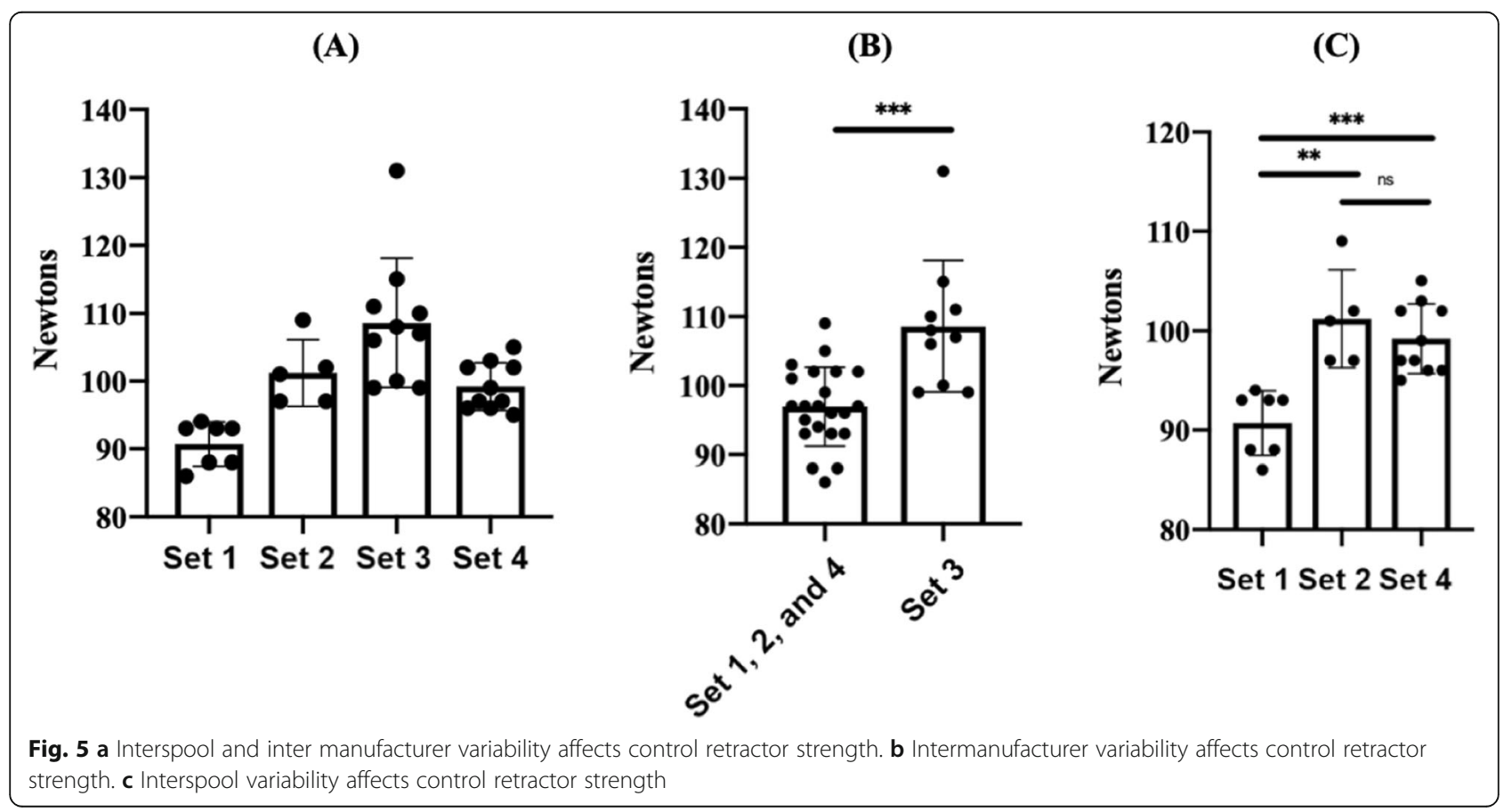




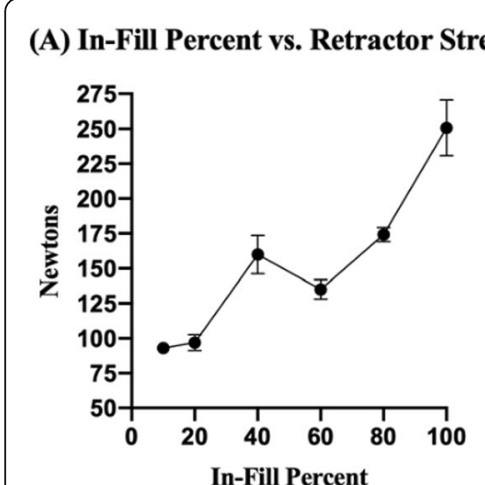

(D) Thickness (in.) vs. Retractor Strength

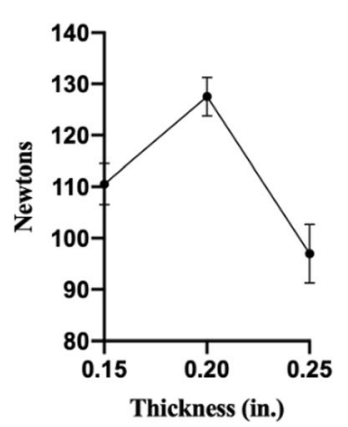

(B) Perimeter Number vs. Retractor Strength

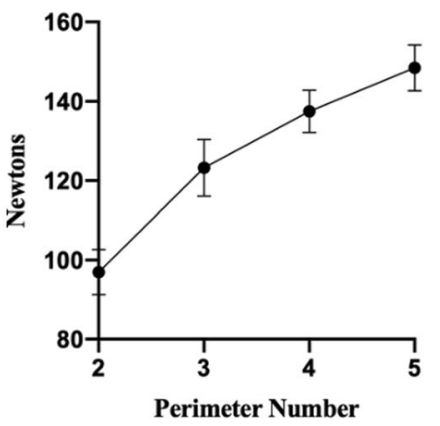

(C) Width (in.) vs. Retractor Strength

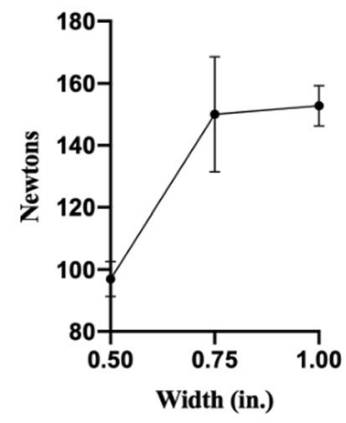

Fig. 6 a As infill percent increases, retractor strength increases with a spike at 40\%. b As perimeter number increases, retractor strength increases. c As retractor width increases, retractor strength increases up to $0.75 \mathrm{in.} \mathbf{d}$ Retractor thickness is most optimal at $0.2 \mathrm{in}$. at $20 \%$ infill. e Increasing retractor thickness increases retractor strength at 100\% infill

pressure through a $0.4 \mathrm{~mm}$ nozzle is in fact a sterilization process [21]. We have data from our lab that shows that post-processing of PLA prints can in fact be processed with steam sterilization, despite prior data that suggest that it would not be possible [24]. This is due to advances in PLA polymer technology and the ability to anneal and crystallize the PLA device after printing. This manuscript is intended as a pre-clinical evaluation and optimization of 3D printing technology. Additional research will be needed to assess performance after steam sterilization, printing with different nozzle diameters, and with different materials.

\section{Abbreviations}

PLA: Polylactic Acid; STL: Standard Tessellation Language

\section{Acknowledgments}

UCSF Department of Orthopaedic Surgery.

The article processing charge for this publication has been funded

generously by the UCSF Open Access Publishing Fund.

\section{Authors' contributions}

JVC planned the experiment, designed the retractors, printed the retractors, collected retractor strength data, and wrote the manuscript. AD assembled and maintained 3D printer, and trained co-authors on 3D printing process. CSL printed the retractors and collected retractor strength data. ABD is the $\mathrm{Pl}$, provided funding, assembled and maintained 3D printer, and trained co- authors on 3D printing process and computer automated design. All authors read and approved the final manuscript.

Funding

UCSF Department of Orthopaedic Surgery.

Availability of data and materials

Retractor STLs and data are available through the authors.

Ethics approval and consent to participate

Not applicable

Consent for publication

Not applicable

Competing interests

Joshua V. Chen - none.

Alexis Dang - Stock Options: Printerprezz.

Carlin S. Lee - none.

Alan BC Dang - Paid employee: Printerprezz; Stock Options: Printerprezz.

Author details

${ }^{1}$ Department of Orthopaedic Surgery, University of California, San Francisco, CA, USA. ${ }^{2}$ Department of Surgery, Orthopaedic Section, San Francisco VA

Health Center, San Francisco, CA, USA. 
Received: 17 July 2019 Accepted: 24 October 2019

Published online: 21 November 2019

\section{References}

1. Abdullah KA, Reed W. 3D printing in medical imaging and healthcare services. J Med Radiat Sci. 2018;65:237-9. https://doi.org/10.1002/jmrs.292.

2. Brown C. 3D printing set to revolutionize medicine. Can Med Assoc J. 2017; 189:E973-4. https://doi.org/10.1503/cmaj.1095442.

3. Dodziuk H. Applications of 3D printing in healthcare. Pol J Cardio-Thorac Surg. 2016;3:283-93. https://doi.org/10.5114/kitp.2016.62625.

4. George M, Aroom KR, Hawes HG, Gill BS, Love J. 3D Printed Surgical Instruments: The Design and Fabrication Process. World J Surg. 2017:41: 314-9. https://doi.org/10.1007/s00268-016-3814-5.

5. Hoang D, Perrault D, Stevanovic M, Ghiassi A. Surgical applications of threedimensional printing: a review of the current literature \& how to get started. Ann Transl Med. 2016;4:456. https://doi.org/10.21037/atm.2016.12.18.

6. Kim GB, Lee S, Kim H, Yang DH, Kim Y-H, Kyung YS, Kim C-S, Choi SH, Kim BJ, Ha H, Kwon SU, Kim N. Three-Dimensional Printing: Basic Principles and Applications in Medicine and Radiology. Korean J Radiol. 2016;17:182. https://doi.org/10.3348/kjr.2016.17.2.182

7. Malik HH, Darwood ARJ, Shaunak S, Kulatilake P, El-Hilly AA, Mulki O, Baskaradas A. Three-dimensional printing in surgery: a review of current surgical applications. J Surg Res. 2015;199:512-22. https://doi.org/10.1016/j. jss.2015.06.051.

8. Mardis NJ. Emerging Technology and Applications of 3D Printing in the Medical Field. Mo Med. 2018:6:368-73.

9. Mishra S. Application of 3D printing in medicine. Indian Heart J. 2016;68: 108-9. https://doi.org/10.1016/j.ihj.2016.01.009.

10. Paul GM, Rezaienia A, Wen P, Condoor S, Parkar N, King W, Korakianitis T. Medical Applications for 3D Printing: Recent Developments. Mo Med. 2018; 115(1):75-81.

11. Shilo D, Emodi O, Blanc O, Noy D, Rachmiel A. Printing the Future-Updates in 3D Printing for Surgical Applications. Rambam Maimonides Med J. 2018;9:e0020. https://doi.org/10.5041/RMMJ.10343.

12. Squelch A. 3D printing and medical imaging. J Med Radiat Sci. 2018;65:1712. https://doi.org/10.1002/jmrs.300.

13. Sun Z. 3D printing in medicine: current applications and future directions. Quant Imaging Med Surg. 2018:8:1069-77. https://doi.org/10.21037/qims. 2018.12.06.

14. Tack P, Victor J, Gemmel P, Annemans L. 3D-printing techniques in a medical setting: a systematic literature review. Biomed Eng OnLine. 2016;15: 115. https://doi.org/10.1186/s12938-016-0236-4.

15. Ibrahim AMS, Jose RR, Rabie AN, Gerstle TL, Lee BT, Lin SJ. Threedimensional Printing in Developing Countries. Plast Reconstr Surg - Glob Open. 2015;3:e443. https://doi.org/10.1097/GOX.0000000000000298.

16. Brennan M, Bokhari F, Eddington D. Open Design 3D-Printable Adjustable Micropipette that Meets the ISO Standard for Accuracy. Micromachines. 2018:9:191. https://doi.org/10.3390/mi9040191.

17. Pavlosky A, Glauche J, Chambers S, Al-Alawi M, Yanev K, Loubani T. Validation of an effective, low cost, Free/open access 3D-printed stethoscope. PLoS One. 2018;13:e0193087. https://doi.org/10.1371/journal. pone.0193087.

18. Rothenberg S, Abdullah S, Hirsch J. 3D Printing Prototypes for Healthcare Professionals: Creating a Reciprocating Syringe. J Digit Imaging. 2017;30: 566-71. https://doi.org/10.1007/s10278-017-9953-x.

19. Visscher DO, te Slaa S, Jaspers ME, van de Hulsbeek M, Borst J, Wolff J, Forouzanfar T, van Zuijlen PP. 3D printing of patient-specific neck splints for the treatment of post-burn neck contractures. Burns Trauma. 2018;6:15. https://doi.org/10.1186/s41038-018-0116-1.

20. Wang J, Yang L, Ma M, Li G, Xu S, Li Q, Xu Z, Liu J, Ye C. Development and Application of a No-Clog Surgical Suction Tip Using 3D Printing Technology. Med Sci Monit. 2018;24:6765-73. https://doi.org/10.12659/MSM. 909900.

21. Neches RY, Flynn K, Zaman L, Tung E, Pudlo N. On the intrinsic sterility of 3D printing. PeerJ. 2016;4:e2661. https://doi.org/10.7717/peerj.2661.

22. Rankin TM, Giovinco NA, Cucher DJ, Watts G, Hurwitz B, Armstrong DG. Three-dimensional printing surgical instruments: are we there yet? J Surg Res. 2014;189:193-7. https://doi.org/10.1016/j.jss.2014.02.020.

23. Anderson JM, Shive MS. Biodegradation and biocompatibility of PLA and PLGA microspheres. Adv Drug Deliv Rev. 2012;64:72-82. https://doi.org/10. 1016/j.addr.2012.09.004.
24. Rozema F, Bos R, Boering G, Van Asten J, Nijenhuis A, Pennings A. The effects of different steam-sterilization programs on material properties of poly(L-lactide). J Appl Biomater. 1991;2:23-8. https://doi.org/10.1002/jab. 770020104

\section{Publisher's Note}

Springer Nature remains neutral with regard to jurisdictional claims in published maps and institutional affiliations.
Ready to submit your research? Choose BMC and benefit from:

- fast, convenient online submission

- thorough peer review by experienced researchers in your field

- rapid publication on acceptance

- support for research data, including large and complex data types

- gold Open Access which fosters wider collaboration and increased citations

- maximum visibility for your research: over $100 \mathrm{M}$ website views per year

At $\mathrm{BMC}$, research is always in progress.

Learn more biomedcentral.com/submissions 